\title{
UNA MUSICALIDAD DE LA FILOSOFÍA DESDE EL BEETHOVEN DE THEODOR ADORNO
}

\author{
Saturnino Expósito Reyes
}

\section{RESUMEN}

Este breve ensayo constituye una reivindicación de la obra que escribió Adorno sobre Beethoven como un texto profundo que arroja luz sobre la comprensión del pensamiento del filósofo. Se focalizará sobre las conclusiones a las que lleva la técnica compositiva tardobeethoveniana y su papel en una reconcepción de la razón que represente un modelo desde el que fundamentar una filosofía del siglo xxi. Se partirá de la distinción realizada por Adorno de las distintas maneras que Beethoven, a lo largo de sus estilos de composición, elaboró para enfrentarse o, más bien, acercarse a distintos momentos y técnicas compositivas dentro de una forma sonata, ahondando en cómo esos usos tardobeethovenianos supusieron una influencia para el pensamiento de Adorno, hasta el punto de esconder la clave del problema adorniano: la superación de la Ilustración a través de la Ilustración misma.

Palabras Clave: dialéctica negativa, estética negativa, filosofía de la música, obra tardía.

\section{A MUSICALITY OF PHILOSOPHY FROM \\ THEODOR ADORNO'S BEETHOVEN}

\section{Abstract}

This short essay constitutes a vindication of Adorno's work on Beethoven as a profound text that sheds light on the understanding of the Frankfurtian's thought. It will focus on the conclusions to which the late Beethovenian compositional technique leads and its role in a reconception of reason that represents a model from which to base a 21 st century philosophy. It will start from the distinction made by Adorno of the different ways that Beethoven, throughout his styles of composition, elaborated to confront or, rather, approach different moments and compositional techniques within a sonata form, delving into how those uses by the Late Beethoven were an influence on Adorno's thought, to the point of hiding the key to the adornian problem: the overcoming of the Enlightenment through the Enlightenment itself.

KEYWORDS: negative dialectic, negative aesthetic, philosophy of music, late style. 


\section{INTRODUCCIÓN: LA VIGENCIA DE UN MARIDAJE ENTRE FILOSOFÍA Y MÚSICA}

La presente investigación se origina por la captación de una necesidad en torno a la elaboración de una reorientación de la racionalidad. Una que contemple un giro hacia un planteamiento más sistemático sobre la idea de musicalidad filosófica, maridaje que además se detecta como un tema de actualidad y relevancia. Este inquirir sobre el plano musical del que podría impregnarse la racionalidad es un camino que se va percibiendo como necesario desde hace ya cierto tiempo. No en vano, el siglo XIX marcó el nacimiento de la musicología como disciplina, a pesar de llevar milenios hablando sobre música, y también fue escenario de filósofos en los que lo musical se constató como algo sustancial: Schopenhauer, Schelling y Nietzsche, para quienes la música constituía un programa filosófico. Y tal influjo se ha seguido sintiendo en autores más contemporáneos como García Bacca y Eugenio Trías, quienes abogan por la urgencia de ese giro musical en la filosofía.

Sin embargo, existe una figura más central para afrontar un estudio sistemático de la relación entre Música y Filosofía, y, con ello, para emprender un camino que lleve hacia la búsqueda de una racionalidad que estuviese alimentada por un giro musical: Th.W. Adorno.

La musicalidad en su obra la constituye como un monumento único y un referente necesario para entablar un estudio de lo musical en la milenaria disciplina de la Filosofía. Para él, la música no es un tema, sino una parte constituyente de su pensamiento. Por ello, establece entre la Música y la Filosofía una relación extremadamente problemática, que no puede llegar a ser salvada con una dicotomía o hegemonía de uno de los polos. Consecuentemente, dicha constelación debe estudiarse otorgándoles voz a los dos pesos de la balanza. Para ello, es funcional la visión que poseía de su pensar "con las orejas», sentencia central para cualquier intento de interpretar su edificio intelectual, pues muestra su naturaleza más esencial: la interdisciplinariedad y lo novedoso de su planteamiento racional, que pretende partir de una escucha estructural.

\section{BEETHOVEN DESDE ADORNO}

Debido a lo vasta que es la materia musical dentro del pensamiento adorniano, es necesaria la concreción del tema. Para ello se ha elegido la figura de Beethoven. El motivo ha sido la particularidad de la visión de Adorno sobre él, quien marcó su despertar musical, y a quien le dedicó treinta ańos de su vida académica en un monográfico que quedó inacabado. Durante todo ese tiempo, su propia obra se vio inspirada por la reflexión acerca del último Beethoven, y viceversa. Pues este libro mil veces anunciado y mil veces postergado no fue una excepción ajena a su pensamiento, ni una rareza histórico-musical alrededor del compositor, sino un libro de filosofía desde el cual problematizar los usos de la razón. Su relevancia queda patente a raíz del interés que suscitó este compositor dentro del canon musical y del templo intelectocompositivo erigido por Adorno. Lo que hace tan 
paradigmática e importante su figura para él es que representaba dos situaciones contrapuestas: tanto el momento de plenitud como final de la música académica. Por un lado, el culmen y, por el otro, la culminación de la tradición musical occidental. En tal sentencia paradójica toman juego los dispares estilos compositivos teorizados por Adorno.

A partir de tal punto de partida, desde este monográfico, el filósofo levanta un monumento a la música entendida como forma de conocimiento. Especifica tal hito en el Beethoven tardío, a quien empareja con su proyecto de pensar con los oídos. Así, no se trata únicamente de una obra histórico-crítica acerca de un compositor, sino de una reflexión filosófica que llevaría a Adorno hacia un pensamiento utópico y de rechazo al sistema cerrado. Por ello, su mirada a Beethoven constituye un elemento crucial desde el cual entender su propio planteamiento filosófico, además de representar esa palanca con la que recuperar el buscado proyecto de un hermanamiento entre filosofía y música.

Dentro de este escrito adorniano, son varias las claves interpretativas que pueden hallarse acerca del compositor. Además, entre todas ellas se establece una constelación, en la que una de ellas, por su propio peso, se constituye como piedra fundacional: el aspecto crítico del Beethoven tardío. El motivo de ello es lo crucial de la contraposición entre los estilos intermedio y tardío que establece Adorno. Esta es la idea sobre la que se compone este breve artículo. La facultad crítica es tan primordial para la estructura de este texto que funciona de tronco primario del que surge el resto de ramas de esa secuoya gigante que constituye la interpretación adorniana del compositor. Se establece así como axiomática. De ella surgen motivos que alimentan la estructura y argumentación del resto de caracteres.

Este poder negativo y crítico del último Beethoven deriva de su disonante relación con el empuje del desarrollo afirmativo de su segundo periodo. De este modo, Adorno presentó ambas fases compositivas como antagónicas. Mientras que creyó que la síntesis heroico-patética del estilo intermedio fue la de la plenitud de lo humano, constituyéndolo como un valedor de la lógica y del absoluto hegeliano, el tardío se alzó como una dura crítica a la idea de armonía estética. Frente a esa obra hegeliana, el estilo tardío creó una perspectiva en la que el mundo revelaba sus grietas, y mostraba toda la tensión y lucha existente y perenne. Su obra tardía fue concebida como autocrítica a un anterior estilo, que se mostraba excesivamente afirmativo y conciliador. Así, todas las categorías del último Beethoven se crearon como desafíos al idealismo.

En toda esta exposición crítica, además, se vislumbran ciertas filiaciones entre Adorno y su interpretación del estilo tardío de Beethoven. Esos frentes comunes muestran el mismo guion crítico con el que ideó su propia obra filosófica y la renovación del sistema de Hegel; es decir, con el que generó un «sistema» que pensaba, a la vez, con Hegel y contra Hegel. Son varios los conceptos sobre los que se derrama ese guion crítico, mostrando en todos ellos la intención de Adorno de mantener en tensión estas dos disciplinas tan diferenciadas en acto, pero que albergan la potencia de una relación verdaderamente dialéctica. La primera pareja de conceptos sería la de sujeto y objeto. 
Desde este binomio formado por lo subjetivo sujeto y lo objetivo, Adorno establece una contraposición entre el Beethoven intermedio y el tardío, mostrando los dispares resultados teórico-filosóficos que alcanzó cada uno de ellos.

Por un lado, la manera compositiva intermedia dio lugar a una exposición análoga a la dinámica y al discurso de la subjetividad del pensamiento hegeliano. Esto lo logró a través de la naturaleza de dos técnicas compositivas:

Primero, la manera en que compuso los temas musicales. Estos, al estar constituidos por simples células indefinidas, eran muy proclives a ser elaborados por el sujeto, quien terminaría formando un complejo laberinto de ideas. Además, tal sencillez y no complejidad temática es lo que posibilitó que Beethoven hubiese podido expandir sus estructuras hasta tiempos no explorados anteriormente. Tal como sucede, por ejemplo, en la Sinfonía ${ }^{\circ}{ }^{\circ} 5$ en do menor, $O p$. 67, donde casi todo procede de esa pequeña célula rítmica que tradicionalmente se ha visto como la llamada del destino. Este tema (desarrollado a partir de un "escuálido» motivo de cuatro notas) es utilizado durante toda la pieza por la mente de Beethoven para cumplir con las más dispares funciones: melodía principal, acompañamiento, material de relleno... Esta multitarea propia de ese simple motivo es lo que lo convierte en un elemento generador y constructor de la forma; es decir, en el componente motriz de cualquiera de las secciones de la pieza. Motor que acciona la mano organizadora de la subjetividad.

Segundo, la forma y naturaleza que le dio a sus secciones de Desarrollo. Estas fueron inclinadas hacia la idea de proceso y lucha, factores que se encarnan en su dinamismo modulatorio. Fue esta sección la que se convirtió en el núcleo desde donde surgieron los grandes cambios de su segundo estilo, lo que la abrió a nuevos e inéditos horizontes de significados. Todo ello lo consiguió gracias a esa movilidad y dynamis con que las impregnó, otorgándoles la apariencia de no atenerse a reglas sobre temas, modulaciones, progresiones, etc. Consecuentemente, dan la sensación de «libertad» en el compositor; es decir, la apariencia de potencialidad que tiene el factor subjetivo. Así, el Desarrollo se forma como un momento para la expresividad de la subjetividad, de ahí que Adorno la haya vinculado con el proceso compositivo del subjetivo Beethoven. En él surge la poderosa mano del compositor, quien retuerce las ideas de la Exposición combinándolas de manera compleja o alternativa.

Estas acciones respecto a la construcción temática y de la sección de Desarrollo se tradujeron en la imagen de un sujeto capaz de organizar la totalidad del trabajo musical, venciendo la contradicción entre identidad y no identidad. Dándose entonces una primacía del sujeto ante la forma. Para Adorno, este se estaría moviendo a través de una lógica hegeliana en la que sujeto y objeto se constituirían dialéctica, holística y expresivamente en una síntesis armónica y positiva. 
En cambio, en la obra tardobeethoveniana se activó un factor crítico que encendió la sospecha ante la anterior unidad afirmativa entre sujeto y objeto. Ahora iría en contra de aquella razón dominadora propia del idealismo. Este cambio de actitud lo llevó a efecto a partir de aspectos musicales como la presentación de lo material y convencional desnudamente, la introducción continua de interrupciones y cesuras que rompen la apariencia de plenitud, y el retorno a la «objetividad» polifónica.

Adorno vio en esto la huida de la idea de una subjetividad lugarteniente, pero no pretendiendo que esta desapareciera. Pues esta aún tenía un papel crucial, uno que ya no consistía en la posesión del material, sino como luz que ilumina desde unas grietas ya no ocultas tras el velo de la apariencia. Las continuas fisuras en el material musical de una pieza tardobeethoveniana es lo que permite que no se dé una renuncia o capitulación del sujeto, ni un concepto de verdad como pura objetividad, sino que ambas estén entramadas en una relación irresoluble. Así, el último Beethoven estaría caracterizado tanto por lo objetivo como por lo subjetivo. Ya ninguno de esos dos pesos de la balanza podría ser superado ni subsumido por el otro. De este modo, la primera característica de esta dialéctica tardía sería su negatividad. El estilo tardío ya no produciría la síntesis armónica, sino que desgarraría los extremos para conservarlos. El objeto se delimita mediante el sujeto y el sujeto se construye mediante sus relaciones objetivas, y tan pronto como fuesen fijados sin tales mediaciones, se convertirían en ideología.

II

Otra pareja de conceptos sobre la que se desarrolla aquella idea que se había presentado como axiomática (el espíritu crítico tardobeethoveniano enfocado hacia su anterior producción) es la del binomio todo/parte. Desde él, vuelve a surgir una dura y férrea contraposición entre los distintos estilos beethovenianos.

Por un lado, en el intermedio se da una hegemonía y verdad del todo que subyuga a la parte, la cual queda relegada a mera inanidad. Con ello, Beethoven llevó a cabo un Tour de forcé. Detuvo la movilidad del Desarrollo en la Reexposición, unificando rigor formal con dinamismo y temporalidad. En tal primacía del todo sobre lo particular (que se considera nulo y vacío), Adorno ve verificada la exuberante idea hegeliana de sistema. Este fue otro de los puntos cruciales en los que se basó el filósofo para establecer ese paralelismo entre Hegel y el compositor.

Sin embargo, que Adorno estipule que en el Beethoven heroico se haya que pensar ante todo en la primacía del conjunto sobre el detalle no significa y conlleva que ese todo sea concebido abstracta y metafísicamente; es decir, como si se tratara de un algo ajeno a lo fáctico de la experiencia. Al contrario, este todo tendría que ser pensado como la suma de particulares, tal y como también observó que sucedía en el sistema hegeliano. Podrían enumerarse en cuatro los puntos cruciales (e interrelacionados) que subrayan el poderío del todo frente a la parte en la música del Beethoven intermedio: 
Primero, el hecho de que la melodía singular claramente escrita ceda ante el flujo del conjunto. Esto se puede detectar, por ejemplo, en el hecho de que en sus obras intermedias no se escucha una conjunción de temas melodiosamente mozartianos, sino unos que van superándose y desarrollándose en su propio dinamismo, conforme avanza la pieza. Esto es posible gracias a que Beethoven no expone unas ideas musicales poseedoras de una identidad propia, sino que están conformadas por un conjunto de mónadas musicales vinculadas técnicamente entre sí. Tal inexistencia de una identidad propia en sus ideas musicales y motivos es lo que ocasiona que lo individual y particular sea una nulidad, algo efímero, pero, al mismo tiempo, es lo que permite su carácter de sublimidad. Este factor explica y resume perfectamente la relación hegeliana entre la parte y el todo que existe en la obra del Beethoven intermedio. Esto es así ya que, debido a esa ausencia de identidad, sus ideas melódicas no pueden sobresalir por sí mismas del proceso global. Al contrario, por su vacuidad, estas necesitan de la totalidad para mostrarse como resultado de todo ese devenir por el que se generan y que generan.

Segundo, además, ese flujo del conjunto musical beethoveniano se dirige a un final afirmativo y reconciliador de todas las fricciones vividas en el desarrollo de la obra; es decir, al estilo hegeliano. Con tal fuerza del todo sobre la parte, y a pesar de lo inseparable de los dos polos del binomio, la lógica discursiva beethoveniana (que vivificó y dinamizó el esquematismo clasicista) cae finalmente en el estatismo al culminar dicho dinamismo con un ademán reconciliador a la manera hegeliana. Lo arquitectónico prima sobre lo dinámico. Esto se detecta perfectamente en la función con la que se idea la sección de Reexposición, que actúa como reconciliación. Precisamente, fue esa reconciliación la que representó para Adorno el lado más oscuro del titanismo beethoveniano. Esta, según él, fue la conexión y complicidad más profunda que tuvo Beethoven con el idealismo y el dialéctico Hegel, en cuyo sistema, al final, la suma de las negaciones (y con ello del devenir mismo) desemboca en la teodicea de la apariencia.

Tercero, el todo actúa desde la sombra. Adorno se sirvió de la voluntad y energía que vislumbró que actuaba por detrás de una obra beethoveniana, para considerar al compositor absolutamente inserto en su visión hegeliana. Tal voluntad y energía no era otra cosa que el todo, el espíritu del mundo hegeliano; es decir, la forma en movimiento. Esta idea hace que el todo de la obra se imponga a la pluralidad de lo vivo, que es lo que, para Adorno, marca la afinidad de toda belleza con la muerte. Esa muerte sería el elemento afirmativo que existe en la negación de los detalles por el todo.

Cuarto, otro aspecto importante para detectar el poderío del todo en esta obra intermedia es la afirmación de que ese todo conlleva una negatividad para con otros, lo cual enciende la crítica adorniana ante ambos autores, tanto la dirigida a Hegel como al Beethoven intermedio. Tal crítica se basa en que la libertad de la Ilustración no es holista, sino que deja a unos desarrapados de su calor. Y así mismo es cantada a viva voz en el $4 .^{\circ}$ movimiento de la Sinfonia $n .^{\circ} 9$ en re menor, $O p .125$, esa obra tardía que en realidad consti- 
tuye una vuelta a su anterior estilo heroico. Tal y como se puede leer en esa musicalización que el compositor hizo del poema de Schiller, esa libertad no es omnipresente, pues no es para todo ser humano. Ese otro que en el poema es instigado a dejar la comunidad y, con ello, negado en beneficio del todo es lo singular, lo particular.

En cambio, al final de su carrera, el discurso no aceptaba ya las directrices de los polos armónicos y todo en él se volvió temático, sin jerarquías o líneas preestablecidas. Todo ello le otorgó libertad formal. Es por ese espíritu revolucionario por lo que el último Beethoven no preparaba ya un segundo tema, ni unía una Reexposición con el Desarrollo. Para él, era mejor elaborar una variación que presentara temas en cada compás y que al final se fundieran en una guirnalda de trinos que ocultara la idea musical. El resultado fue una polarización y lucha entre el todo y la parte, que dio lugar a un paisaje petrificado que no conducía a un camino cómodo. Ese pedregoso sendero es el de la irresoluble confrontación del todo y la parte. Desde esta no eliminación de la polaridad, los fragmentos ofrecen un testimonio del granítico bloque que es el secreto íntimo del último Beethoven: la célula más pequeña de la realidad vista pesa tanto como el resto del mundo. De ahí que su forma tendiese al fragmento, y que su música ya no intentara alcanzar una unidad totalizadora entre lo discontinuo y lo dispar.

Para llegar a tal conclusión, Adorno estudió el material musical empleado por el último Beethoven que constituía una recuperación de lo particular. Todo ello, con la finalidad de determinar críticamente esa relación auténticamente dialéctica entre la parte y el todo. Los materiales que encontró son:

Primero, el empleo del trino, al que le dio un papel central, convirtiéndose, según Adorno, en la mayor recuperación de lo particular realizada por Beethoven. Para el filósofo, los trinos son la expresión más pura del cliché vacío y del floreo intrascendente. Sin embargo, observó cómo Beethoven, al final de su carrera musical, rehízo y cambió su naturaleza de un modo que terminaron perdiendo su condición ornamental. Con él, dejaron de ser un mero adorno para convertirse en un motivo esencial. Así, aquel simple material decorativo típico del Barroco se convirtió en algo tan importante y crucial que hubo ideas compuestas «sobre» su diseño, sometiendo, luego, todo aspecto estructural y narrativo a su mecanismo. De este modo, el último Beethoven presentó al trino como una idea regulativa, lo que hizo que desapareciera casi por completo como adorno. Ahora iba a ser sumergido en la esencia de la composición, adoptando otro tipo de funcionalidad. Este profundo cambio en su naturaleza tiene que significar algo trascendente.

Segundo, con las variaciones, Beethoven atendió a lo «infinitamente» pequeño en sus últimas obras. Él las convirtió en un rasgo prominente de su tercer periodo, y las cargó con un significado absolutamente nuevo, lejos del habitual mero embellecimiento y del replanteamiento contemplativo de una idea musical a través de los simples elementos melódicos y armónicos. Vio en esta técnica formal la capacidad de ofrecerle a una obra la oportunidad de que sus 
extremos se tocaran hasta un límite desconocido, en el que conviviera el movimiento perpetuo con la estaticidad. En definitiva, una relación entre el todo y la parte en la que la síntesis constructiva (aparentemente inquebrantable) se disolviera en fragmentos casi inapreciables.

La variación, gracias a su énfasis en lo nimio, es capaz de plantarle cara a la totalidad, surgiendo un modo de actuar contemplativo y opuesto al desarrollo dialéctico de las ideas temáticas del periodo medio. Este despliegue de variaciones en las últimas piezas beethovenianas significó una nueva forma de entender la estructura y, por lo tanto, una nueva forma de «enfrentarse» a la totalidad y de replantearse la relación entre el todo y la parte. Esta, durante su anterior estilo, había culminado con la concepción del todo de una forma hegeliana; es decir, como lo verdadero. En cambio, ahora, en el estilo tardobeethoveniano, se ve que ya no busca un equilibrio afirmativo entre los extremos, sino la polarización de ambos. Ni la subsunción de lo individual al todo, ni la desaparición de una totalidad, pues estos constituirían actos antidialécticos. La totalidad es fundamental para el pensamiento dialéctico. Parece como si el Beethoven tardío se hubiera planteado ese pensar contra Hegel, pero al mismo tiempo con Hegel, que emprendería más tarde Adorno.

Tercero, el empleo de las cesuras que fisuran y fragmentan las estructuras de Beethoven. Estas son como una red de grietas en el abrupto y objetivo paisaje, por las que se cuela fugazmente una dañada subjetividad. Serían entonces, todas esas fisuras y brechas en la superficie que fragmentan la música tardía de Beethoven. Ello hace de ellas unos agentes de la fragmentación que aparecen e intervienen con una violencia abismal para cortar la realidad musical, justamente, en donde deberían estar sus articulaciones. Estas cesuras desde las que estalla la subjetividad son sumamente esenciales en la gramática musical del Beethoven tardío, un espectro de mecanismos que se extendió a un nivel arquitectónico y global. Entonces, pasan a ser un estrato normativo y categórico.

Cuarto, la fragmentariedad y yuxtaposición de las ideas musicales también constituye otro de esos materiales musicales estudiados por Adorno desde los que veía que se daba una recuperación de lo particular. Este, además, es un factor ya «visible» ante la mera escucha. Tal énfasis en lo fragmentario hace que sus obras estén efectuadas con austeridad y mostrando una naturaleza desgarrada. Con ello, Beethoven se alejó del mero gusto, presentándose como la primera gran rebelión de la música contra lo decorativo, además de como un músico crítico.

Una consecuencia de esa fragmentariedad es la desaparición de toda la «conducción trabajosa» tan propia de su etapa anterior. Ahora ya no se halla el tejido, la diligencia agitada, ni el empeño por llevar las cosas a su plenitud, que se relaciona con una huida de la mera apariencia.

Otra consecuencia es que los temas están constituidos por motivos muy repartidos. Ya no constituyen entonces propiamente melodías ni estructuras independientes. Así, los temas tienden a subdividirse en densos aforismos 
o en pequeños organismos que no se sabe adónde conducen, no sirviendo ya consecuentemente de hilo conductor. Asimismo, esta fragmentariedad de los temas termina extendiéndose al global de la estructura. Lo fraccionario de las propias ideas revierte en el total de las piezas, y en cómo los distintos temas se suceden, uno tras otro, sin una preparación o transición convencional. Dan lugar a lo que podría ser denominado como una composición constelativa.

Quinto, existe una tendencia hacia la forma "abierta» ${ }^{1}$. Con esta terminología se está queriendo poner el énfasis en la concepción de la totalidad como algo no cumplido, pues ella no es más que una mera apariencia de integridad. Tal tendencia hacia la forma abierta debió presentarse como resultado de la recusación del último Beethoven a la idea de una totalidad entendida como algo ya consumado, algo que es pura y abstractamente intelectual. Una totalidad que debió de presentársele como algo insoportable. De ahí que en su obra tardía lo singular ya no fuera más un caso o ejemplo de lo universal, sino su encarnación misma, al cual remitiría y haría presente al mismo tiempo. Por medio de esta renuncia a la universalidad esquemática y alienantemente intelectual, Beethoven abogó por la colisión entre lo singular y lo universal; superando, así, esa esquematización de una forma concebida como unilateralmente trascendental y que, por lo tanto, hubiera huido de la colisión entre extremos. Para realizar tal acción y escapar de una forma concebida como completamente consumada, puso en un juego dialéctico y en contrapunto a distintas formas musicales, las cuales habían corrido distinta suerte a lo largo de la historia de la música académica occidental. En esta conjunción de distintas formas musicales que daría lugar a una forma «abierta», tuvo un papel central la mayor atención que le prestó a los procedimientos de las variaciones y la polifonía, lo que promovió a su vez una incursión en la fuga. Así, tanto la fuga como la variación representaron unas de esas antiguas formas que fueron vistas por el último Beethoven desde una nueva perspectiva y a las que, además, permeó con formas más actuales (véase la forma sonata). Todo este juego intermórfico dio como resultado unos híbridos que irían más allá de las esclerotizadas formas cerradas y esquemáticas, $\mathrm{y}$ de unas formas abiertas entendidas contingentemente.

${ }^{1}$ Hay que diferenciar estas formas abiertas que se están nombrando ahora de aquellas como el rondó, que "con la no vinculación intencional de la alternancia entre estribillo y estrofas, es una forma decididamente abierta» (GS 7, 328). Aquí en cambio esa apertura sería tomada desde otra perspectiva, una más dialéctica entre distintas formas que dan lugar a la aporía de una apertura de la forma pero sin caer en la contingencia. Por ello, y para distinguirlas visualmente, se emplean usando entrecomillado. 
Un nuevo concepto sobre el que vuelve a actuar esa idea axiomática que recorre el global de la interpretación adorniana sobre Beethoven es el de convención. En torno a él vuelve a establecerse una nueva contraposición entre ambos estilos.

Por un lado, en las obras intermedias, la relación entre subjetividad y convención está marcada por la dialéctica hegeliana entre el amo y el esclavo, donde la segunda, la convención, es subjetivada, transformada según su propia intención. En tal concepción no había lugar para las convenciones, quedando todo bajo la expresión de la subjetividad y circunscrito al postulado de la identidad. El estilo heroico-patético beethoveniano mostró una imagen subjetivista en la que todos los cambios acaecidos en su manera de componer representaron una novedad radical, una sacudida en el significado mismo de la estructura tradicional. En tal concepción de la composición, no habría lugar, o este sería escaso, para las convenciones, lo que actúa como indicador de un subjetivismo ciego, que está guiado únicamente por los impulsos de su propia razón. Su procedimiento «subjetivista» consistía en introducir y transformar las figuras tradicionales de acompañamiento en la dinámica subjetiva, no soportando ninguna convención y remodelando las inevitables con la impetuosidad de la expresión. Así, el Beethoven intermedio tomó la convención y la llenó con subjetividad.

En cambio, durante el estilo tardío, Beethoven ya no representaría una subjetividad ciega que creara sin tener en cuenta el material de la obra, sino todo lo contrario. A partir de una nueva concepción de racionalidad que no pretendía imponer el sujeto al material de la obra, su música no habla el lenguaje del individuo. Este nuevo modo de acción se traduce en que las convenciones sean abandonadas de una manera aparentemente despreocupada. Ya no están integradas a la fuerza en un lenguaje uniforme, sino que destacan como cuerpos extraños. Esto fue posible gracias a que la subjetividad ya no hacía estallar a la obra para expresarse a sí misma, sino que la abandonaba dejando que se mostrara desnudamente. La convención ya no era evitada ni coartada subjetivamente, sino que ahora se hacía visible en una desnudez no disimulada ni trasformada. Son dejadas ser. Las convenciones se volvieron expresivas, favoreciéndose la interacción entre elementos estilísticos y arcaísmos, y dándoles un mayor peso en el global de la pieza. Se daría, así, una extensión de la pluralidad de reglas, y consecuentemente una mayor heterogeneidad y fragmentariedad. Su obra tardía tomaría la forma de un paisaje volcánico y disgregado, capaz de desvelar la apariencia.

Esta relación entre las convenciones y la subjetividad debe ser entendida como la ley formal de la que surge el contenido de sus últimas obras, siendo el poder de la subjetividad el gesto triunfal con el que se abandona a la obra. Esta subjetividad hace estallar a la obra, no para expresarse a sí misma, sino para despojarse inexpresivamente de la apariencia del arte. Ese estallido deja ruinas tras de sí, y la única posibilidad que posee el sujeto para darse a conocer es el actuar de forma cifrada desde los vacíos de los que brota. Los desgarros y las grietas allí contenidos son el testimonio de la impotencia final del yo ante el ser. De ahí el exceso de materia y de convenciones ya no penetradas ni sometidas por la subjetividad. Con ello se evi- 
dencia que el sujeto ha abdicado frente a la fuerza superior de la realidad externa, y se define a sí mismo reconociendo indirectamente su propia muerte.

IV

Todo lo visto en el anterior punto se realizó poniendo hincapié en lo axiomático de las convenciones. Axiomáticas porque sobre ellas descansan otras proposiciones de Adorno sobre la música de Beethoven, como por ejemplo la dialéctica existente en su visión del pasado, en la que los polos de la regresión y el progreso quedan relacionados en un juego paradójico, donde lo arcaico puede ser regenerador. Esta idea se completa ahora en este punto articulándola a través de las concepciones de memoria y utopía. Se profundiza así en la relación de esos dos conceptos con la música beethoveniana.

Durante todo su análisis sobre la obra tardía de Beethoven, Adorno intentó edificar una filosofía fundada desde la memoria. No solamente una filosofía de la música, sino una que cayera en la esencialidad del pasado. Ello no solo para permanecer vuelto a lo pretérito y contemplar sus injusticias, sino para hallar en él motivos para la esperanza. Según Adorno, la mirada melancólica es el índice de un cambio de perspectiva necesario. El duelo por aquello que desapareció y que no llegó a realizarse preserva una idea de felicidad que permite conservar la distancia frente al statu quo.

La filosofía de la memoria es planteada como una vuelta hacia atrás, a la vez que orienta el futuro. La memoria revela que el pasado no ha concluido, que su potencial no se ha agotado. Este sigue vivo y esperando porque sus sueños no se han realizado aún. Está preñado de posibilidades. La nostalgia que sus vías muertas despiertan se transforma en esperanza de futuro, porque nutren la confianza en algo diferente que realice lo que el pasado no llegó a ser.

En la tensión entre el pasado y el futuro, las reflexiones de Adorno y del Beethoven tardío no expresaron el ensimismamiento en el pesimismo, sino la confianza en la ampliación de horizontes. Por ello, la memoria no se limita a criticar o compadecerse, sino que recupera cuanto ha sido sometido por la razón totalitaria.

Si el dominio consiste en el olvido de lo dominado, la memoria se convierte en la única capaz de vencerlo. Así pues, una filosofía y una música que se antojen críticas deben ir en busca de argumentos, ideas y posibilidades entre lo desechado para reconstruirlas. Vueltos hacia atrás buscan motivos de esperanza para el porvenir.

Por ello, lo nuevo no debe negar lo anterior, sino que se dice siempre en relación con lo antiguo. Lo nuevo no es una categoría subjetiva, ni fruto de la intencionalidad. En eso es en lo que consistiría visto desde la perspectiva del Beethoven intermedio. En cambio, ese nuevo tendría un cariz diferente, procedente de la pugna entre lo objetivo y lo subjetivo, tal como sucede en la obra tardobeethoveniana. Pasado y futuro están codeterminados, por ello, el valor que se atribuye a la tradición determina el sentido de lo nuevo y viceversa.

Lo que el Beethoven tardío, cargado de todas estas características, significa para Adorno es lo mismo que debió percibir Benjamin con el Angelus novus de Klee. Debió de verlo como un ángel de la historia, que le sirviera como crítica al 
concepto de progreso. El ángel de la historia quiere detenerse a ayudar a los seres humanos que se hallan en un panorama de destrucción acumulada, a la vez que una terrible tormenta (que sopla desde el paraíso) le impide cerrar sus alas para descender y socorrerlos. Tal analogía se basa en la visión ofrecida por Adorno sobre el estilo tardío como la de un poseedor de unos ojos ante los que el pasado se mostraba como un paisaje en ruinas. Es por ello por lo que, por su espíritu crítico, para Adorno, Beethoven se alejaba del carácter dominante de la época, dando un giro retrospectivo. Ambos, el ángel y un Beethoven tocado por la mano de la muerte, se niegan a quitar la vista del panorama de destrucción que los seres humanos acumulan tras de sí, y se muestran reacios a seguir el camino marcado por la línea recta de la idea de progreso.

Concretamente, Beethoven, con esa «recuperación» del pasado y el uso de la convención, presenta la memoria como una fuerza capaz de transformar el futuro, y de suscitar imágenes de lo «otro» posible. Con tal potencia, la memoria es la única que permite que tanto la filosofía como la música se alimenten de lo marginado y lo olvidado. Con tal movimiento e idoneidad, la memoria es la única capaz de revelar que la historia no está constituida por una única línea de progreso, ni por un gran Relato único. Al contrario, ello permite ver su pluralidad. Al mantener esa concepción plural, se motiva que haya que establecer perspectivas en las que el mundo revele sus grietas y precipicios, y en las que este se muestre tal y como alguna vez habrá de aparecer: monstruoso y desfigurado. La obra tardía de Beethoven es uno de estos ejemplos. Y ello es así gracias a que la tensión de lo irresoluble se convierte en su contenido fundamental. Su música tardía ya no está dispuesta a pactar con lo real, pero, a su vez, tampoco está preparada para dejar de sońar con un futuro. Mantiene en tensión y de manera no resolutiva todos los momentos temporales: pasado, presente y futuro.

\section{CONCLUSIÓN}

En este breve ensayo, se ha pretendido exponer el patrón de la dialéctica y de la constelación conceptual que se halla alrededor de Adorno y Beethoven. Para ello, el contenido elaborado no se articuló solamente en un análisis interpretativo y explicativo de la teoría filosófica musical adorniana, ni tampoco en una mera observación técnica musical del método compositivo de Beethoven. Al contrario, el contenido expuesto se preocupa por integrar ambos paneles en una actividad dual en la que es imposible discernir en qué consiste el trabajo de cada uno de ellos, pues son inseparables. Es imposible saber dónde acaba uno y comienza el otro. En el pensamiento de Adorno, los mundos de la música y la filosofía se iluminan entre sí en una polarización donde es imposible distinguir sus límites.

Esa ha sido la finalidad perseguida, aunque centrada en Beethoven. Se ha tratado de descifrar lo que Adorno pudo ver en él, de seguir su discurso para así observar en qué medida lo adoptó. En este periplo, se han establecido ciertas similitudes entre ambos, siendo la mayor su empeño por no suavizar las tensiones. Eso fue lo que encontró en el Beethoven tardío, su sospecha de la unidad entre lo sub- 
jetivo y lo objetivo y de la totalidad generada por el movimiento. En definitiva, de todo lo que había conferido autenticidad a su obra anterior.

Con tal esfuerzo, presentó a un Beethoven tardío que vivía en un mundo sin certezas, que intentaba superar no con una poderosa subjetividad que redujera el objeto a sí misma, sino a través de convenciones; partiendo del objeto y presentando lo material desnudamente. Presentó a la obra tardobeethoveniana como ignición entre unos extremos que ya no soportaban un centro seguro; tal como presentaba su propia labor filosófica.

Ambos forman una constelación en la que se pone en juego la música y la filosofía de una manera inseparable. Es por ello por lo que no se puede extraer al filósofo de sus análisis musicales, ni al músico de su pensamiento teórico, pues ambos son en su relación, no por separado. Tanto la filosofía como la música y, más concretamente, tanto Adorno como Beethoven quedan imbuidos en una relación como la que existe entre lo subjetivo y lo objetivo, donde no quedarían bien dibujados los límites, y en la que tanto uno como otro podrían actuar de fuente o destino.

En la figura de Beethoven, Adorno vio la posibilidad y capacidad de realizar un proyecto interdisciplinar entre la música y la filosofía que no culminara en una mera síntesis entre ambas disciplinas, sino en una filosofía "auxiliada» por análisis musicológicos, y en una estética musical impregnada por el espíritu dialéctico-crítico. Con este procedimiento dialécticamente negativo, Adorno estaría apuntando hacia la tarea de una búsqueda de la musicalidad que pudiera habitar en la filosofía. De ahí que se haya pretendido llegar al pensamiento de Adorno desde un análisis musicológico de su visión de Beethoven y viceversa. Pues, y tal como él mismo afirmaba, actualmente no se puede componer como Beethoven, pero, en cambio, sí se debe pensar como él componía. Su pensamiento tiene un potencial que no hay que dejar escapar. Su importancia no recae únicamente en qué se dice, sino en cómo. Es decir, en el estilo de composición, el cual proporciona ya bastante: la forma como filosofía, basamento desde donde podría comenzar a edificarse una filosofía del siglo XXI. Si esto es algo más que una audaz analogía, debería significar que el pensamiento es capaz de generar un estilo en el que puede hacerse cargo de lo ausente; es decir, en el que puede disponer sin violencia de la alteridad imprevisible y hacer elocuente lo que apenas se deja nombrar. 
